\title{
Minimally invasive bicuspid aortic valve repair with external ring annuloplasty
}

\author{
Oleg I. Orlov ${ }^{1}$, Vishal N. Shah ${ }^{1}$, Cinthia P. Orlov ${ }^{1}$, Vasily I. Kaleda ${ }^{2}$, Konstadinos A. Plestis ${ }^{1}$ \\ ${ }^{1}$ Department of Cardiothoracic Surgery, Lankenau Medical Center, Wynnewood, PA, USA; ${ }^{2}$ Department of Cardiac Surgery, Central Clinical \\ Hospital, Moscow, Russian Federation \\ Correspondence to: Dr. Konstadinos A. Plestis. System Chief, Department of Cardiothoracic and Vascular Surgery, Lankenau Medical Center, Main \\ Line Health, 100 E Lancaster Avenue, Wynnewood, PA 19096, USA. Email: dplestis@gmail.com.
}

Submitted Mar 08, 2019. Accepted for publication May 06, 2019.

doi: 10.21037/acs.2019.05.06

View this article at: http://dx.doi.org/10.21037/acs.2019.05.06

\section{Clinical vignette}

A 65-year-old man with hypertension presented with shortness of breath and III/IV diastolic murmur. Transesophageal echocardiogram (TEE) showed a bicuspid aortic valve with prolapse of the conjoint right (RC) and non-coronary (NC) cusp. Severe eccentric aortic regurgitation (AR) directed towards the anterior leaflet of the mitral valve was also noted. The measurements of the aortic annulus, sinuses of Valsalva and sinotubular junction (STJ) were 32, 40 and $34 \mathrm{~mm}$ respectively.

\section{Surgical technique}

\section{Preparation}

The procedure was performed in supine position under general endotracheal anesthesia with standard cardiac hemodynamic monitoring. External defibrillation pads were placed.

\section{Exposition}

A 6-cm J-type mini-sternotomy from 2-cm inferior to the sternal notch to the midpoint of the $3^{\text {rd }}$ intercostal space and exiting to the right was performed. The ascending aorta was directly cannulated using the Seldinger technique under TEE guidance. The right common femoral vein was cannulated and the cannula was advanced into the superior vena cava using the Seldinger technique under TEE guidance. After aortic cross-clamping, 1 liter of CustodiolHTK cardioplegia (Essential Pharmaceuticals LLC, Ewing,
NJ, USA) was given antegradely in the aortic root. An additional 1-liter dose of Custodiol-HTK cardioplegia was infused directly into the coronary ostia after the root was opened. A pulmonary arterial vent was placed. The aorta was transected $1 \mathrm{~cm}$ above the sinotubular junction. Fullthickness 4-0 polypropylene traction sutures were placed at the level of the three commissures and the sutures were placed under tension. The aortic valve was inspected and found suitable for repair.

\section{Operation}

Root dissection started at the nadir of the NC sinus and continued to the NC/left coronary (LC) commissure. Dissection continued underneath the left main coronary artery (LMCA) toward the LC/RC commissure. In this area, dissection is restricted by the muscular septum. Dissection continued along the RC sinus and underneath the right coronary artery separating the right ventricular fibers from the annulus. Dissection proceeded toward the $\mathrm{RC} / \mathrm{NC}$ commissure. In this area, dissection is limited by the membranous septum. The right coronary artery was mobilized adequately for ring placement. Eleven pledgeted 2-0 Ethibond ' $U$ ' stitches were placed from inside out in the subvalvular plane starting at the nadir of the NC sinus and proceeding clockwise. No stitch was placed under the LMCA.

Due to limitations of external dissection at the LC/ $\mathrm{RC}$ and $\mathrm{RC} / \mathrm{NC}$ commissures, sutures were placed along the lowest portion of the root at these locations. Once all sutures were passed, the native aortic annulus diameter 
was measured with a Hegar dilator. A \#29 Tailor flexible annuloplasty ring (St. Jude Medical, St. Paul, MN, USA) $6 \mathrm{~mm}$ larger than the desired annular diameter (typically $23 \mathrm{~mm}$ for men and $21 \mathrm{~mm}$ for women) was selected. To achieve a $23 \mathrm{~mm}$ annular diameter, a $29 \mathrm{~mm}$ ring was tied around a $23 \mathrm{~mm}$ Hegar dilator within the aortoventricular junction using Cor-Knot (LSI Solutions, Victor, NY, USA). After ring placement, the cusps were inspected and Schäfers caliper (Fehling Instruments, Karlstein, Germany) was used to measure the effective height of the LC cusp. Free edge plication of the LC cusp was necessary to achieve an effective height of $10 \mathrm{~mm}$. Closure of the cleft in the conjoint cusp was then performed using interrupted 6-0 polypropylene suture establishing a free margin length of the conjoint cusp equal to the free margin length of the LC cusp. After placing the cusps in a closed position, the water test was used to assess the competency of the valve. The STJ was stabilized using a $31 \mathrm{~mm}$ band, which was secured with 4-0 polypropylene pledgeted sutures.

\section{Completion}

The aortotomy was closed with continuous 5-0 polypropylene suture incorporating the STJ band. The patient was weaned from cardiopulmonary bypass. TEE showed no evidence of residual AR. The effective height was $13 \mathrm{~mm}$. Sternal closure was achieved with a combination of rigid plate fixation (Zimmer Biomet, Warsaw, IN, USA) and sternal wires typically with two plates and two wires.

\section{Comments}

The patient had an uncomplicated hospital course. He remains asymptomatic and free of AR at 1-year followup. Mini-sternotomy extending to the $3^{\text {rd }}$ or $4^{\text {th }}$ intercostal space provides excellent exposure to the proximal aorta. In general, the intercostal space located adjacent to the aortic valve as seen in the coronal section on preoperative computed tomography scan is identified and the intercostal space above is entered. A critical technical step to facilitate exposure includes placement of pericardial traction sutures to bring the aorta to the midline and near the top of the incision. Also, it is important to avoid the right internal mammary artery and vein. A single two-liter dose of Custodiol-HTK cardioplegia is used to establish complete myocardial protection for approximately one and a half hours (1). In cases with moderate-to-severe AR, a 1-liter dose is administered in the aortic root and an additional 1-liter is directly infused into the coronary ostia.

Annular stabilization is critical after bicuspid aortic valve repair. A preoperative annular diameter greater than or equal to $28 \mathrm{~mm}$ risks early recurrent $\mathrm{AR}$ and subsequent failure. Three main annular stabilization techniques are subcommissural annuloplasty, external subannular aortic ring and more recently, internal geometric ring annuloplasty. In subcommissural annuloplasty, annular reduction is limited to the interleaflet triangle. Late annular re-dilatation can occur particularly in patients with bicuspid valves leading to the recurrent AR. External subannular aortic ring is effective at reducing annular dimensions and stabilizing the repair in midterm follow-up. Moreover, Ko et al. report greater annular reduction and improved transvalvular gradients after external subannular aortic ring placement as compared to subcommissural annuloplasty (2).

We favor the use of greater than six subannular stitches to minimize aortoventricular junction expansion between sutures $(3,4)$. We also use an expansible aortic ring to preserve the natural dynamics of the aortic annulus. In order to reduce cusp stresses and restore the proper STJ/annulus ratio to approximately 1.2 , we routinely place an external STJ band, particularly if the STJ is dilated. Weaknesses to our technique include the need for deep external root dissection, coronary mobilization and reconstruction of annular geometry in a two-dimensional plane. Threedimensional geometric ring annuloplasty may potentially provide more physiological annular remodeling (5). Finally, we avoid placing the ring underneath the LMCA to prevent the potential risk of occlusion or injury to the left anterior descending and circumflex arteries.

\section{Acknowledgments}

None.

\section{Footnote}

Conflicts of Interest: The authors have no conflicts of interest to declare.

\section{References}

1. Garbade J, Davierwala P, Seeburger J, et al. Myocardial protection during minimally invasive mitral valve surgery: strategies and cardioplegic solutions. Ann Cardiothorac Surg 2013;2:803-8.

2. Ko H, Bavaria JE, Habertheuer A, et al. Functional 
Outcomes of Type I Bicuspid Aortic Valve Repair With Annular Stabilization: Subcommissural Annuloplasty Versus External Subannular Aortic Ring. Ann Thorac Surg 2019;107:68-75.

3. Basmadjian L, Basmadjian AJ, Stevens LM, et al. Early results of extra-aortic annuloplasty ring implantation on aortic annular dimensions. J Thorac Cardiovasc Surg 2016;151:1280-5.e1.

Cite this article as: Orlov OI, Shah VN, Orlov CP, Kaleda VI, Plestis KA. Minimally invasive bicuspid aortic valve repair with external ring annuloplasty. Ann Cardiothorac Surg 2019;8(3):441-443. doi: 10.21037/acs.2019.05.06
4. de Kerchove L, Mosala Nezhad Z, Boodhwani M, et al. How to perform valve sparing reimplantation in a tricuspid aortic valve. Ann Cardiothorac Surg 2013;2:105-12.

5. Rankin JS, Mazzitelli D, Fischlein T, et al. Geometric Ring Annuloplasty for Aortic Valve Repair During Aortic Aneurysm Surgery: Two-Year Clinical Trial Results. Innovations (Phila) 2018;13:248-53. 